\title{
Single-Atom Catalysis: How Structure Influences Catalytic Performance
}

\author{
Gareth S. Parkinson ${ }^{1}[\mathbb{C}$
}

Received: 1 January 2019 / Accepted: 5 February 2019 / Published online: 25 February 2019

(c) The Author(s) 2019

\begin{abstract}
It now seems clear that supported metal adatoms can be effective catalysts for some reactions, but how to make best use of this phenomenon remains an open question. Most studies to date have focussed on synthesizing stable "single-atom" variants of functioning supported nanoparticle systems, but there is mounting evidence that the properties of supported adatoms do not scale from those of larger nanoparticles in a simple way. The sensitivity of the adsorption properties to the charge state and coordination environment of the adatom has led researchers to dream that single atom catalysis (SAC) can bridge the gap between heterogeneous and homogeneous catalysis, opening the door to a new generation of highly-selective catalysts for difficult reactions. To make this dream a reality, a fundamental understanding of how the structure of the active site affects the adsorption properties of adatoms is essential. Since the active site geometry cannot be unambiguously determined from realistic SAC systems at present, experiments on precisely-defined model systems must work hand-in-hand with theory to provide a fundamental basis for this rapidly growing field.
\end{abstract}

\section{Graphical Abstract}

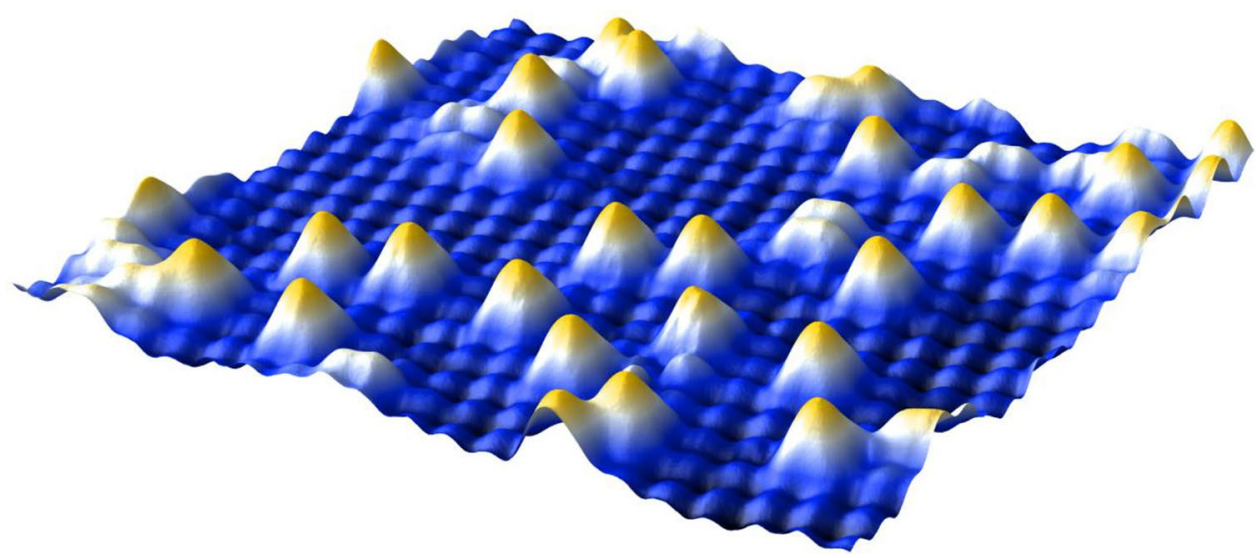

Keywords Single-atom catalysis $\cdot$ Surface science $\cdot$ Scanning tunneling microscopy $\cdot$ IRAS

The field of "Single-atom catalysis" [1-7] came about as the ultimate limit of the ongoing effort to minimise the amount of precious metal required in heterogeneous catalysts. Although driven by economic considerations, the transition from nano and even subnano metal particles supported

Gareth S. Parkinson

parkinson@iap.tuwien.ac.at

1 Institute of Applied Physics, TU Wien, Vienna, Austria on inexpensive materials has yielded fascinating science, including the remarkable discovery that $\mathrm{Au}$, the noblest of metals, becomes catalytically active in nano form [8]. Pioneering experiments with size-selected clusters have contributed significantly to our understanding of the size effect (see for example [9-12]), and such studies provided some of the earliest evidence that the smallest possible supported nanoparticle, an isolated adatom, could be catalytically active [13]. In 2003, Flytzani-Stephanopoulos and coworkers 
[14] went one step further: They noticed that an Au/ceria catalyst exhibited similar water-gas shift activity when the metallic nanoparticles were leached away, and concluded that strongly bound, ionic Au species were responsible all along. Over time, this phenomenon has been demonstrated to occur on other metal oxide supports including titania and iron oxide [15].

Today, many groups intentionally synthesize catalysts based solely on "single-atom" active sites. Not only does this make the most efficient use of precious metal, but if all active sites are the identical, selectivity problems associated with a inhomogeneous particle size distribution can be avoided. A common approach is to select a system for which nanoparticles are active, e.g. Pt for $\mathrm{CO}$ oxidation, and then create a stable "single-atom" variant. This is not straightforward, because a strong thermodynamic driving force causes adatoms to sinter into larger nanoparticles on metal oxide surfaces, but it is now routinely achieved. Comprehensive summaries of the different synthesis methods have been published recently $[1,16]$, and I will not attempt to summarize them here. I will, however, briefly describe the method of Zhang and coworkers, who coined the phrase "single-atom catalyst" to describe a $\mathrm{Pt}_{1} / \mathrm{FeO}_{\mathrm{x}}$ system prepared by a wet chemical approach in 2011 [7]. Rather than leaching away the metallic component, their catalyst and support were co-precipitated from solution containing $\mathrm{H}_{2} \mathrm{PtCl}_{6} \cdot \mathrm{H}_{2} \mathrm{O}$ and $\mathrm{Fe}\left(\mathrm{NO}_{3}\right)_{3} \cdot 9 \mathrm{H}_{2} \mathrm{O}$. Fine tuning of the temperature and $\mathrm{pH}$ was required to obtain the atomic dispersion, together with an extremely low Pt loading [0.17 weight percent (wt\%)]. Samples with a slightly higher loading $(2.5 \mathrm{wt} \%$.) already exhibited Pt nanoparticles [7]. Following extraction, drying, and calcination (primarily to remove the precursor ligands), the "single-atom" catalyst exhibited excellent low-temperature $\mathrm{CO}$ oxidation activity compared to both Pt nanoparticles and a nano-Au standard. Based on density functional theory (DFT) calculations, the authors proposed the unique catalytic activity originated in the relatively weak binding of $\mathrm{CO}$ to cationic Pt adatoms. A Mars-van Krevelen (MvK) mechanism was proposed, whereby the oxygen to oxidise $\mathrm{CO}$ is initially extracted from the support lattice, and the resulting oxygen vacancy subsequently repaired by $\mathrm{O}_{2}$ supplied from the gas phase [7]. Note that this differs significantly from $\mathrm{CO}$ oxidation on Pt nanoparticles, where molecular $\mathrm{O}_{2}$ dissociates on neighbouring Pt sites facilitating a direct reaction with CO. Another novel approach, pioneered by Datye and Wang, is to trap highly mobile Pt adatoms undergoing Oswald ripening at high binding energy sites on ceria [5, 17]. The resulting catalysts are remarkably stable and effective for $\mathrm{CO}$ oxidation, and interest in the field continues to grow at a rapid pace (Fig. 1).

It is important to note, however, that the concept of single-atom catalysis has been controversial. Ding et al. [19], for example, published a paper in which they claimed that

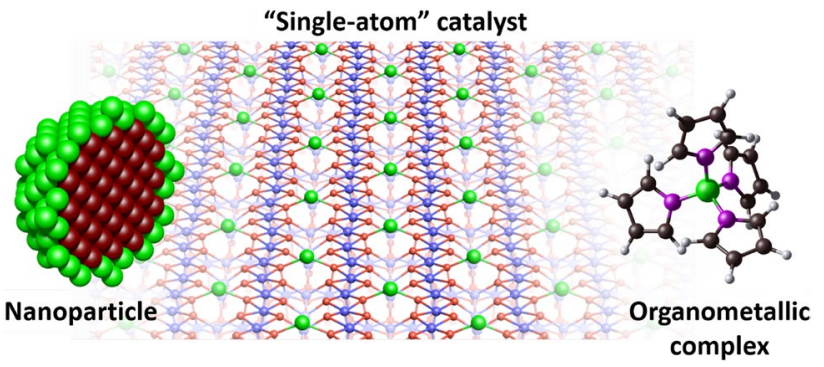

Fig. 1 Single-atom catalysis represents the ultimate limit to the downsizing of precious metal nanoparticles. In the ideal scenario, all metal atoms can be utilized for reactions, and all active sites are identical. The charged metal centre bound to surface atoms has seen SAC systems likened to the organometallic complexes utilized in homogeneous catalysis. Figure adapted from Ref. [18]

isolated Pt atoms are actually inactive for both low-temperature $\mathrm{CO}$ oxidation and water-gas shift chemistry, and that any catalytic activity probably arose from metallic Pt nanoparticles. Infrared reflection absorption spectroscopy (IRAS) data were presented to show that $\mathrm{CO}$ binds more strongly to cationic Pt than metallic Pt clusters, not weaker as Qiao et al. [7] had proposed. In both these works, the as-prepared catalysts were imaged using scanning transmission electron microscopy (STEM), as has become the standard in experimental SAC studies [20]. The resolution of this technique has progressed tremendously over recent years, and adatoms and clusters can be distinguished from the support by virtue of a strong atomic number contrast in high-angle annular dark-field (HDAAF) mode [20]. In both cases, IRAS data exhibited a CO stretch above $2100 \mathrm{~cm}^{-1}$, consistent with binding to cationic $\mathrm{Pt}$ [21], while X-ray absorption near edge structure (XANES) data suggested that Pt was most likely coordinated to oxygen, with no sign of Pt-Pt bonding. The directly opposing conclusions of these two studies highlight a major issue in the SAC field today; it is extremely difficult to unambiguously prove the active species in catalysts based on adatoms and subnano clusters. Even if a catalyst is shown to be atomically dispersed initially, it may evolve in operando and there is no guarantee it remains in this state when reactivity is measured.

Recent work from Phil Christopher's group appears to shed new light on the origin of the controversy discussed above. In this work [22, 23], extremely low Pt loadings $(0.05 \mathrm{wt} \%)$ were deposited onto $5 \mathrm{~nm}$ anatase $\mathrm{TiO}_{2}$ nanoparticles in solution such that, on average, each particle contained just one Pt adatom. Thus, the risk of in situ sintering is substantially reduced. Following calcination in flowing air at $450{ }^{\circ} \mathrm{C}$ for $4 \mathrm{~h}$ to remove ligands from the Pt-precursor, an extremely sharp absorption band was observed at $2112 \mathrm{~cm}^{-1}$ in IRAS, and assigned to cationic Pt occupying a highly homogeneous adsorption site (see Fig. 2). Interestingly, however, temperature programmed desorption (TPD) 
experiments showed that the $\mathrm{CO}$ desorbs from such samples already at $5{ }^{\circ} \mathrm{C}$, in apparent agreement with the conclusion of Qiao et al. [7]. Samples prepared with a higher loading exhibited the behaviour expected for Pt clusters, a broad band below $2100 \mathrm{~cm}^{-1}$ and $\mathrm{CO}$ desorption well above room temperature. Crucially, when the clustered samples were pre-oxidised prior to $\mathrm{CO}$ adsorption, the $\mathrm{CO}$ stretch shifted back above $2100 \mathrm{~cm}^{-1}$, indicative of cationic $\mathrm{Pt}$, but the $\mathrm{CO}$ remained adsorbed up to $300{ }^{\circ} \mathrm{C}$ in TPD. The authors therefore conclude that weakly bound $\mathrm{CO}$ is associated with cationic adatoms, and strongly bound $\mathrm{CO}$ with cation-like $\mathrm{CO}$ stretch is due to adsorption on small $\mathrm{PtO}_{\mathrm{x}}$ clusters. This discussion highlights that the local binding environment plays a defining role in the strength of the interaction with $\mathrm{CO}$, not the charge state. It is thus insufficient to attribute catalytic activity to $\mathrm{Pt}^{2+}$ species, for example, because many different geometries can coexist with similar charge state, and perhaps only one might be catalytically active. In any case, assigning charge states of Pt based on the $\mathrm{CO}$ stretch is problematic, as the measured shift has been shown to depend on the local geometry [21]. To make the most of SAC, we need to determine the atomic-scale structure of the optimal active site, and then figure out how to promote this on the catalyst.

Unfortunately, precise determination of the active site geometry on a real single atom catalyst is extremely difficult. From STEM experiments, we do know that the heavy metal atoms appear congruent with the cation lattice of the metal-oxide support, which suggests coordination to oxygen. This is consistent with XANES data, and DFT calculations, which generally find greater stability with coordination to oxygen. Unfortunately, the lighter oxygen atoms are not well imaged in STEM, and even if they were, any surface specific rearrangement of the lattice around the adatom would be impossible to discern because the images are a $2 \mathrm{D}$ representation of the $3 \mathrm{D}$ object. For a full discussion of the strengths and weaknesses of STEM for SAC studies, see ref [20]. Although some information on the coordination number can be derived from XANES, reliable interpretation requires significant homogeneity on the sample, which is probably not the case on a real catalyst, and relevant reference data for comparison. In general, it is probably fair to say that the primary source of local structural information in SAC is DFT-based calculations.

The theoretical approach to modelling SAC typically takes low-index surfaces as representative of the support. In their extensive studies of " $\mathrm{FeO}_{\mathrm{x}}$ " supported SACs, for example, $\mathrm{Li}$ and coworkers [24] utilize an oxygen terminated $\alpha-\mathrm{Fe}_{2} \mathrm{O}_{3}(0001)$ surface, and adsorb metal adatoms where the next $\mathrm{Fe}$ cation would reside if the bulk structure were continued. This adsorption site is in qualitative agreement with the STEM results described earlier [20], but it is important to note that there is no direct evidence from experiment that the support has this particular stoichiometry or structure following calcination. Since the real support material consists of small nanoparticles it likely exhibits a high density of different step, kink, and point defects that might be expected to bind adatoms more strongly than regular terrace sites. Moreover, the presence of adsorbates such as water and hydroxyls is not considered, nor the possibility of any remnant ligands from the liquid phase preparation. Nevertheless, such calculations demonstrate that it is plausible for $\mathrm{CO}$ oxidation to occur via a Mars-van Krevelen type mechanism at the temperatures observed experimentally, with the rate limiting step linked to extraction of lattice oxygen from the support to form $\mathrm{CO}_{2}$. Recently, Li's group performed a systematic
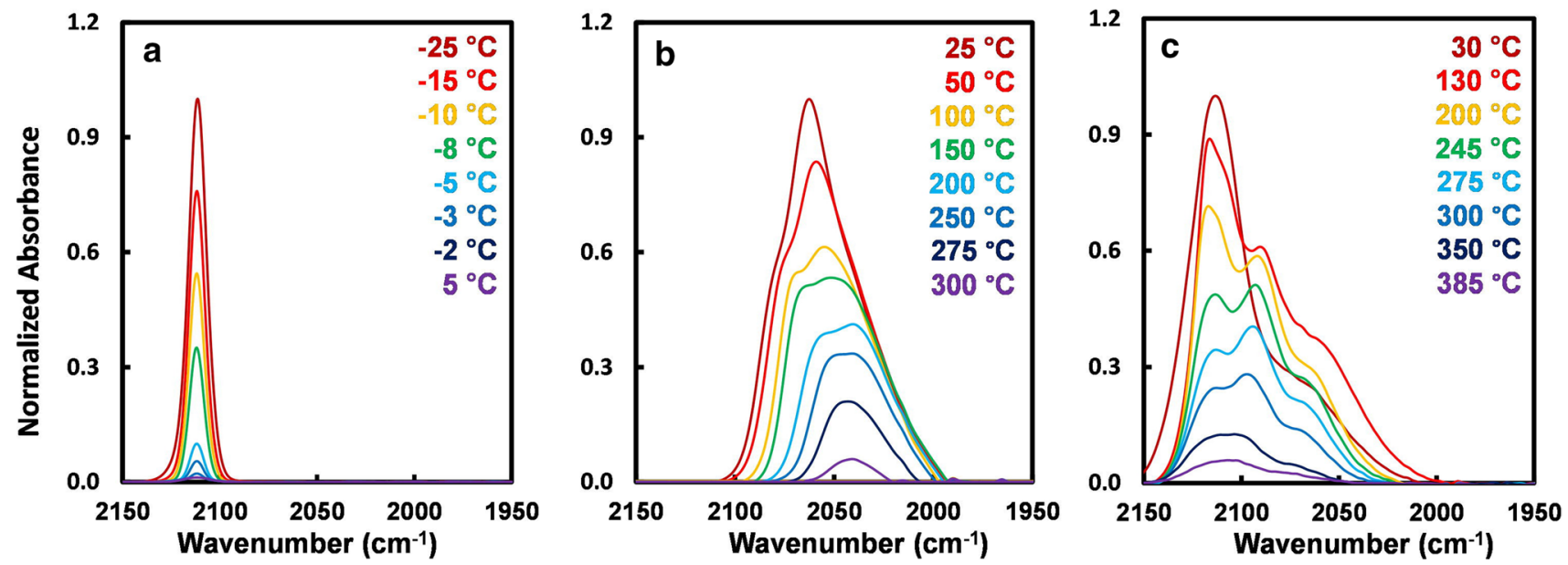

Fig. 2 CO TPD-IR spectra from catalysts based on Pt adatoms (a), Pt clusters (b) and oxidised Pt clusters (c) supported on nano-TiO ${ }_{2}$. The $\mathrm{CO}$ stretch from $\mathrm{Pt}_{1}$ adatoms at $2113 \mathrm{~cm}^{-1}$ is extremely sharp, suggestive of a homogeneous adsorption site, and $\mathrm{CO}$ is weakly bound.

CO adsorbed on oxidised Pt clusters exhibits a similar peak position, but the band is significantly broader. CO binds most strongly to oxidised Pt clusters. Figure reproduced with permission from Ref. [23] 
study of $\mathrm{M}_{1} / \mathrm{FeO}_{\mathrm{x}}$ SACs $(\mathrm{M}=\mathrm{Pt}, \mathrm{Pd}, \mathrm{Ni}, \mathrm{Fe}, \mathrm{Cu}, \mathrm{Co}, \mathrm{Ru}, \mathrm{Rh}$, $\mathrm{Ag}, \mathrm{Os}, \mathrm{Ir}, \mathrm{Au}$ ) for $\mathrm{CO}$ oxidation [24], and concluded that a high $\mathrm{CO}$ adsorption energy correlates with a high barrier for $\mathrm{O}_{\text {lattice }}$ extraction. This is clearly something that could be tested in TPD experiments with a well-chosen model system, as will be discussed in what follows. Interestingly, $\mathrm{Pd}_{1}$ and $\mathrm{Ni}_{1}$ are predicted to perform at least as well as $\mathrm{Pt}_{1}$ for $\mathrm{CO}$ oxidation, with rate determining steps significantly lower than $1 \mathrm{eV}$. Since the properties of adatoms do not scale from those of nanoparticles, it is not clear that Pt need be the best adatom metal for $\mathrm{CO}$ oxidation. Thus, instead of merely reducing the amount of $\mathrm{Pt}$ required, using isolated adatom geometries may provide a route to eliminate it entirely in some cases.

In a similar computational screening study, Li et al. [25] independently investigated the $\mathrm{FeO}_{\mathrm{x}}$ supported system and proposed that $\mathrm{Rh}_{1}, \mathrm{Pd}_{1}, \mathrm{Ru}_{1}$ and even $\mathrm{Ti}_{1}$ and $\mathrm{Co}_{1}$ have the potential to outperform $\mathrm{Pt}_{1}$ for $\mathrm{CO}$ oxidation via a Langmuir Hinshelwood-type mechanism. In this process, $\mathrm{CO}$ and $\mathrm{O}_{2}$ initially adsorb on the same adatom (see step E2, Fig. 3), before (step E5) $\mathrm{CO}_{2}$ desorbs having reacted with one $\mathrm{O}$ atom from the adsorbed $\mathrm{O}_{2}$ molecule. In step E7, a second $\mathrm{CO}$ adsorbs to react with the remnant $\mathrm{O}$ atom. Such a mechanism has yet to be confirmed experimentally, but a stable $\mathrm{Rh}_{1}(\mathrm{CO})_{2}$ dicarbonyl species has been observed in the $\mathrm{Rh}_{1} / \alpha-\mathrm{Al}_{2} \mathrm{O}_{3} \mathrm{SAC}$ system [26]. The ability to adsorb multiple molecules simultaneously to the same adatom will likely depend strongly on its coordination to the support, and is key to the idea that SAC systems can function like homogeneous catalysts.

To better understand the role of coordination in SAC it makes sense to perform experiments on model single-atom catalysts, where the structure of the support and the geometry of the adatom can be precisely determined. The so-called "surface science" approach, based on single-crystal supports and tightly controlled conditions, has contributed significantly to our understanding of heterogeneous catalysis, but as yet there have been relatively few studies addressed to SAC. One reason for this is that metal adatoms are known to rapidly agglomerate when metal is evaporated onto a model metal-oxide support-usually a clean, low index single-crystalline surface-under ultrahigh vacuum (UHV) conditions. This already suggests that the stable adatoms encountered in SAC are most likely not the adatoms adsorbed at regular lattice sites often assumed in theoretical calculations. Indeed, Datye and coworkers $[5,17]$ specifically utilize such high binding energy sites in their recent work to trap mobile $\mathrm{Pt}$ species emitted from larger nanoparticles on ceria at elevated temperature, and the resulting catalyst is highly active for $\mathrm{CO}$ oxidation. There is substantial evidence from surfacescience experiments and theoretical calculations that $\mathrm{Pt}^{2+}$ adatoms are extremely stable in highly coordinated at $\mathrm{PtO}_{4}$ centres at steps on $\mathrm{CeO}_{2}(111)$ [27]. Defects such as oxygen vacancies, cation vacancies, and steps are clearly very important, and the ability to identify and even selectively create different defects by surface scanning probe microscopies makes this approach ideal to study the phenomenon using surface-science techniques in the future.

In this author's group, the $\mathrm{Fe}_{3} \mathrm{O}_{4}(001)$ surface is utilized as a model support. A unique subsurface reconstruction essentially creates an array of strongly binding defect sites (periodicity $0.84 \mathrm{~nm}$ ), on which metal adatoms of almost any variety bind with a twofold coordination to lattice oxygen [28]. The DFT-determined structure has been confirmed by quantitative low-energy electron diffraction (LEED) [28] and surface X-ray diffraction (SXRD) [29] experiments, and the adatom geometry inferred from scanning tunnelling microscopy images was verified by normal incidence X-ray standing waves (NIXSW) experiments and DFT calculations [30, 31]. A major benefit of this model system is that the stability and reactivity of different metals can be compared in a direct manner. So far, we have found that $3 \mathrm{~d}$ transition metals are extremely stable against thermal sintering on $\mathrm{Fe}_{3} \mathrm{O}_{4}$, but tend to incorporate into the surface layer at elevated temperature
Fig. 3 Theoretically predicted reaction pathway of $\mathrm{CO}$ oxidation on $\mathrm{M}_{1} / \mathrm{Fe}_{2} \mathrm{O}_{3}(0001)$ $(\mathrm{M}=\mathrm{Ru}, \mathrm{Rh}, \mathrm{Pd}, \mathrm{Co}$, and $\mathrm{Ti})$ via the Langmuir-Hinshelwood mechanism. Color scheme: M, gold; $\mathrm{C}$, grey; $\mathrm{O}$ of $\mathrm{O}_{2}$, orange; $\mathrm{O}$ of $\mathrm{CO}$, pink; $\mathrm{O}$ of the ironoxide support, red; Fe, purple. Figure reproduced with permission from Ref. [25]

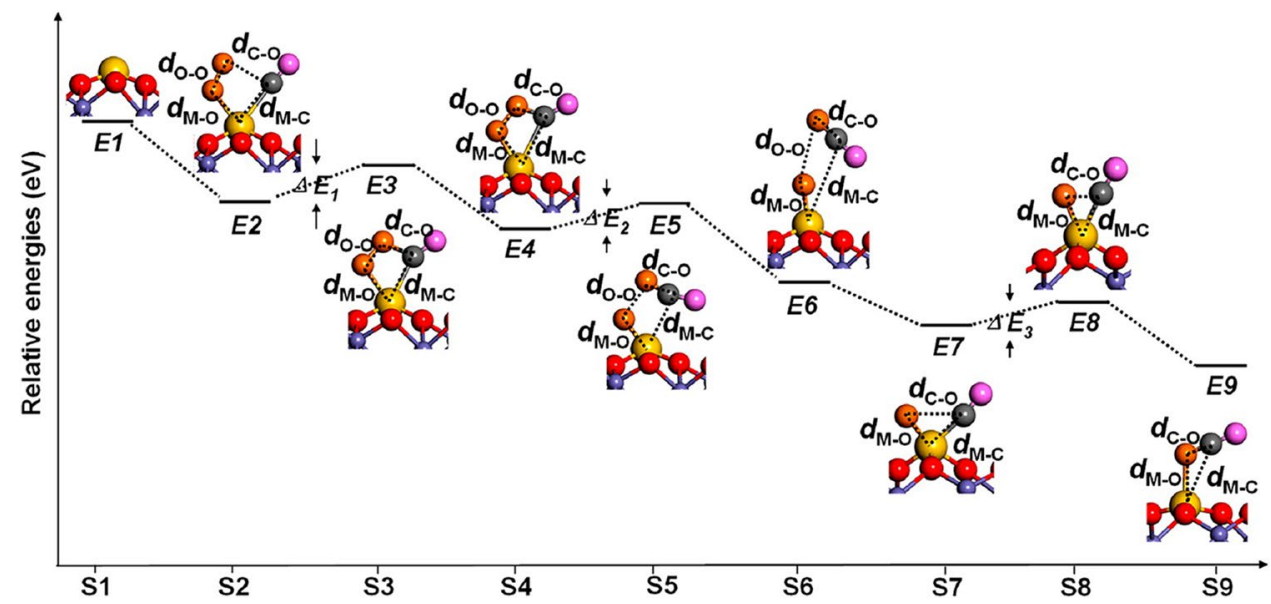


[32]. This is easy to understand because these metals form stable $\mathrm{MFe}_{2} \mathrm{O}_{4}$ ferrite compounds, and thus transition from the twofold coordination to a more stable octahedral site when sufficient thermal energy is supplied [32]. Metals such as Au [33], Ag [34] and Pt [35] do not incorporate in the spinel lattice, and remain stable as adatoms until the reconstruction is lifted thermally at $700 \mathrm{~K}$ [36]. Our DFT calculations suggest that the stability of the adatom phase is not due to a lack of mobility, but rather because the dimers tend to be highly unstable on this surface, which prevents formation of a critical cluster nucleus [34, 35]. Thermal stability is drastically reduced in the presence of pre-existing nuclei, however, which efficiently capture mobile adatoms and rapidly grow in size.

Recent HDAAF-STEM experiments on real SAC systems have observed enhanced $\mathrm{Pt}_{1}$ mobility in reactive gas atmospheres [37]. One of major conclusions of our work on $\mathrm{Fe}_{3} \mathrm{O}_{4}(001)$ is that $\mathrm{CO}$ adsorption destabilizes otherwise stable adatoms by weakening their interaction with the substrate. Figure $4 \mathrm{a}$ shows a $\mathrm{Pt}_{1}$ adatom as calculated by $\mathrm{DFT}+\mathrm{U}$, and panels $\mathrm{B}$ and $\mathrm{C}$ show the effect of $\mathrm{CO}$ adsorption. The double lobed appearance of $\mathrm{Pt}_{1} \mathrm{CO}$ in STM in paned $\mathrm{C}$ is due to two equivalent geometries with a small barrier for switching. Figure $4 \mathrm{c}$ shows selected frames from an STM movie, in which the CO-induced sintering of 4 adatoms into a $\mathrm{Pt}_{4}$ cluster was directly observed. STM, and increasingly noncontact AFM $[38,39]$, are extremely powerful tools and ideal for tracking surface specific processes with exquisite detail. Since this technique relies on having a relatively flat support, applying it directly to nano-sized supports 'real' SACs is not an option.

In the case of $\mathrm{Pd} / \mathrm{Fe}_{3} \mathrm{O}_{4}(001)$ [41], $\mathrm{CO}$ adsorption leads to rapid sintering into large particles, but for $\mathrm{Pt}$, a large proportion $(\approx 50 \%)$ of stable $\mathrm{Pt}_{2}$ dimers are obtained (an example is labelled $\mathrm{Pt}_{2}$ in Fig. 4c). The $\mathrm{Pt}_{2}$ dimers remain as long as the $\mathrm{CO}$ is adsorbed, and decay back into two adatoms when the system is heated above $500 \mathrm{~K}$ [35]. Interestingly, we find from XPS and DFT that the $\mathrm{Pt}_{1}$ adatoms are close to neutral on the surface, but $\mathrm{CO}$ adsorption leads to significant electron transfer into the substrate. Thus, an IRAS experiment would have suggested a cationic charge state. This observer effect has been reported previously for Au adatoms on $\mathrm{MgO}$ [42], and it is thus important to recognise that $\mathrm{CO}$ adsorption can significantly modify the electronic properties of a system, as well as induce reconfiguration or diffusion.
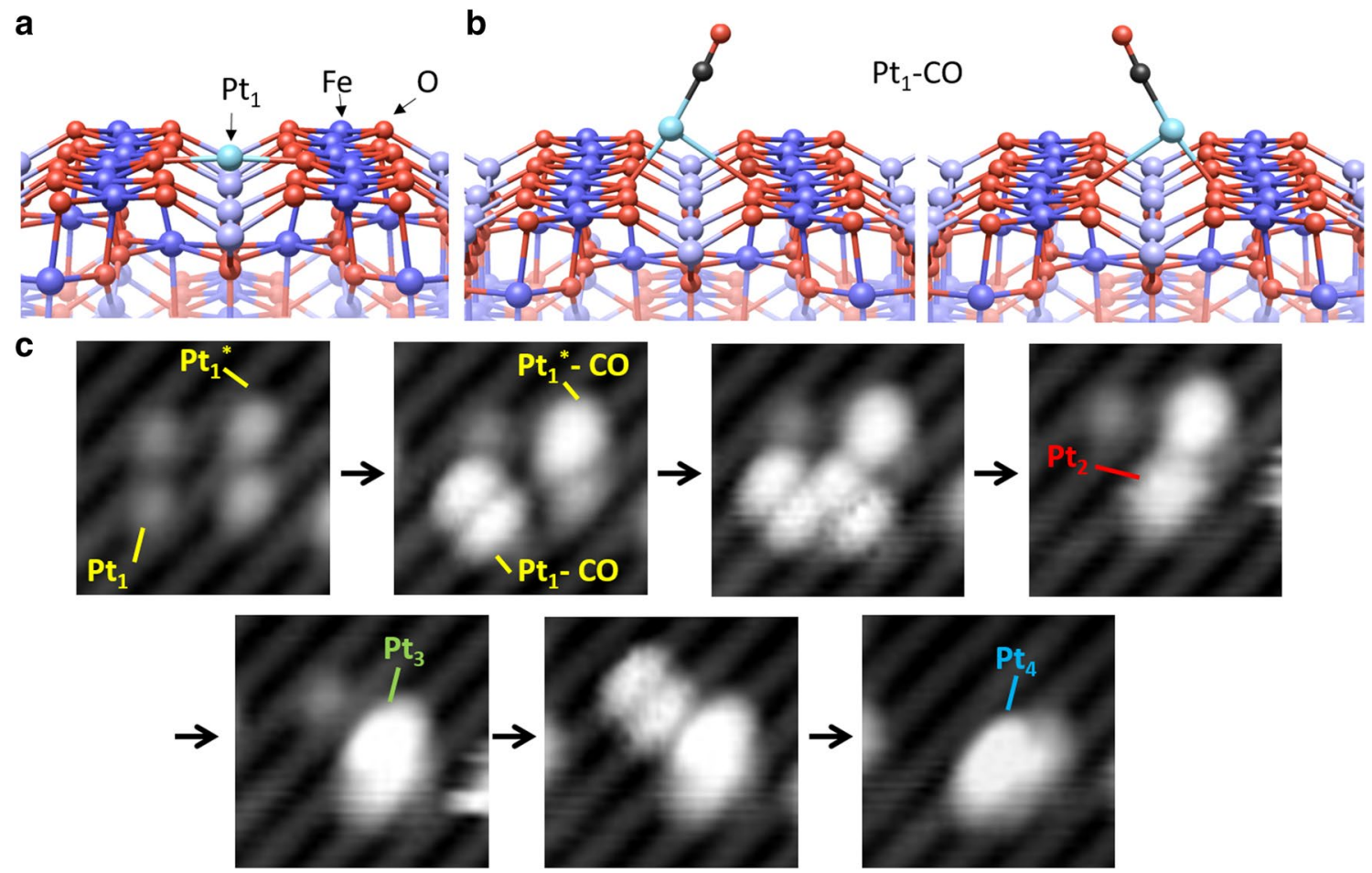

Fig. 4 CO-induced $\mathrm{Pt}$ diffusion and coalescence on $\mathrm{Fe}_{3} \mathrm{O}_{4}(001)-$ $(\sqrt{ } 2 \times \sqrt{ } 2) R 45^{\circ}$. a The energetically preferred $\mathrm{Pt}_{1}$ geometry is twofold coordinated to surface oxygen atoms across neighboring rows (A metastable geometry $(\mathrm{Pt} 1 *$ ) in which $\mathrm{Pt}$ is bound to two $\mathrm{O}$ atoms along the row is not shown). b Adsorption of a CO molecule lifts the $\mathrm{Pt}$ atom from the surface, resulting in a $\mathrm{Pt}-\mathrm{CO}$ species that switches rapidly between two symmetrically equivalent configurations at room temperature. This produces a double-lobed appearance in STM. c STM image sequence acquired during exposure to $2 \times 10^{-10} \mathrm{mbar}$ $\mathrm{CO}$ showing the formation of a Pt tetramer: $\mathrm{CO}$ adsorption on $\mathrm{Pt}_{1}$ and $\mathrm{Pt}_{1}{ }^{*}$, mobility, and coalescence are observed atom by atom. Figure adapted from Ref. [40] with permission from the authors 
To study the effect of coordination, it would be interesting to compare the properties of metal adatoms on other facets of $\mathrm{Fe}_{3} \mathrm{O}_{4}$. For example, a prior STM investigation has shown that $\mathrm{Au}$ adatoms are likely cationic and stable at room temperature under UHV conditions on $\mathrm{Fe}_{3} \mathrm{O}_{4}(111)$, and $\mathrm{CO}$ adsorption was observed at $260 \mathrm{~K}$ [43, 44]. Theoretical calculations predict strong binding of various metals in a threefold coordinated site on this surface [45], and this site is similar to the geometry utilized by Li et al. [25] for their calculations of $\mathrm{FeO}_{\mathrm{x}}$. It would be fascinating if their predictions regarding coadsorption could be verified on a model system, and if so, it would be desirable to collect benchmark IRAS spectra to allow such species to be detected in real SAC systems. One final note on iron oxides; the $\mathrm{Fe}_{3} \mathrm{O}_{4}(111)$ surface mentioned above was prepared by mild reduction of a $\alpha-\mathrm{Fe}_{2} \mathrm{O}_{3}(0001)$ single crystal $[43,44]$, which demonstrates the ease with which the iron oxides transition between different stoichiometry at the surface in different environments. In general, it would be interesting to learn how calcination affects the structure and stoichiometry of UHV-prepared surfaces, and whether the stability and reactivity of metal adatoms is modified.

The Sykes group at Tufts University have focussed on an altogether different model system, employing a $\mathrm{Cu}_{2} \mathrm{O}(111)$-like thin film grown on $\mathrm{Cu}(111)$ as a model support. Their combination of STM, DFT and IRAS data clearly show that isolated adatoms predominate at low coverage in this system, and isotopically labelled TPD spectra conclusively demonstrate that $\mathrm{CO}$ oxidation occurs at $345 \mathrm{~K}$ via a MvK mechanism. Following the TPD, the system deactivates because Pt diffuses under the oxide skin and alloys with the $\mathrm{Cu}$. Interestingly, the $\mathrm{CO}$ stretch associated with single atoms appears below $2100 \mathrm{~cm}^{-1}$, and this, combined with XPS and DFT evidence, led the authors to conclude the $\mathrm{Pt}$ adatoms are adsorbed in a neutral charge state. As discussed above, it is generally thought that Pt adatoms derive their stability from bonds to oxygen, and thus become cationic. Studies on model systems, however, show this is not always the case. It must be noted that the Pt adatom geometry on the $\mathrm{Cu}_{2} \mathrm{O}$ thin film, proposed on the basis of STM and DFT data, has $\mathrm{Cu}$ nearest neighbours and the metallic $\mathrm{Cu}$ bulk in close proximity, and thus is perhaps not representative of the bulk metal oxides typically used as catalyst support. It does show however, that there are interesting alternatives to be explored. Since Mars-van Krevelen type reactions seem prevalent in such systems, it makes sense to investigate highly reducible supports, such as surface oxides, where oxygen is weakly bound.

In this authors opinion, one aspect of SAC that requires detailed study is the role of water. In a follow up the their work on $\mathrm{Pt} / \mathrm{TiO}_{2}$ [23], Christopher's group collaborated with Pacchioni and coworkers to investigate the structural motif that might be responsible for the isolated Pt adatoms causing the extremely sharp CO stretch observed in Fig. 2a. Based on a comparison of theoretically calculated vibrational frequencies, they conclude that geometries based on the stable anatase $\mathrm{TiO}_{2}(101)$ termination, with or without steps, cannot explain the observed vibrational and thermal stability of the adsorbed CO. Incorporation within the lattice, which might be expected to underlie the high stability of the isolated $\mathrm{Pt}$ species, is also incompatible with the experimental data. The best agreement was achieved when additional $\mathrm{O}$ atoms are included in the geometry, which the authors propose can be supplied from the large amount of surface $\mathrm{OH}$ groups that will be omnipresent on the surface under operating conditions.

Another hint of the importance of water comes from the recent work of Datye and coworkers [46], who have shown that pre-treatment of a $\mathrm{Pt} / \mathrm{CeO}_{2}$ catalyst with steam results in a highly active $\mathrm{SAC}$ system. They propose $\mathrm{OH}$ bound at $\mathrm{Pt}^{2+}$ centres to be directly involved in the $\mathrm{CO}$ oxidation mechanism, and their DFT-determined reaction pathway (shown in Fig. 5) has a rate limiting energy barrier of $52 \mathrm{~kJ} \mathrm{~mol}^{-1}$. Initially, one $\mathrm{O}_{\text {lattice }} \mathrm{H}$ species coordinated with a $\mathrm{Pt}$ atom $\left(\mathrm{Pt}^{2+}\right)$ reacts with $\mathrm{CO}$ adsorbed on $\mathrm{Pt}$, creating an oxygen vacancy. This is then filled by adsorption of an oxygen molecule, and $\mathrm{CO}_{2}$ is generated via the deprotonation of the carboxyl intermediate; a process assisted by the newly adsorbed oxygen molecule. Subsequently, the $\mathrm{OOH}$ species (intermediate $\mathrm{V}$ ) reacts with the second adsorbed $\mathrm{CO}$, generating another $\mathrm{CO}_{2}$ molecule with a smaller activation barrier (TS3). Finally, the atomically dispersed surface is recovered after $\mathrm{CO}_{2}$ desorption. Such a mechanism is in line with the experiments of Wang et al. [47], who used isotopic labelling experiments to show that a significant proportion of the $\mathrm{CO}_{2}$ created by a $\mathrm{Pt}_{1} / \mathrm{CeO}_{2}$ catalyst contains oxygen supplied from water, and not from the oxide. They also propose $\mathrm{CO}$ to react with a hydroxyl to form a carboxyl intermediate, which then dehydrogenates with the help of a lattice hydroxyl to generate $\mathrm{CO}_{2}$. Sykes, McEwen and coworkers recently showed that water readily dissociates at $\mathrm{Pt}$ cations in their $\mathrm{Pt} / \mathrm{Cu}_{2} \mathrm{O}$ model system [48].

Clearly, the presence of water in the environment must be considered in models of "real" SACs, and understanding the effect of water on the $\mathrm{CO}$ oxidation reaction mechanism is a realistic target for model studies. In the present authors view, the anatase $\mathrm{TIO}_{2}$ model system is particularly attractive because preparation of a clean well-ordered anatase $\mathrm{TiO}_{2}(101)$ surface is relatively straightforward under UHV conditions [49], oxygen vacancies can be created at will [50], the adsorption of water is well characterized [51, 52], and it is already clear that Pt adatoms are not stable at regular lattice sites [53]. With all these ingredients at hand, it should be possible to validate whether the controlled introduction of water has a direct impact on the adsorption and 
Fig. 5 Proposed reaction mechanism for $\mathrm{CO}$ oxidation on the steam treated $\mathrm{Pt} / \mathrm{CeO}_{2}(111)$ surface. The structures of intermediates and transition states (TSs) correspond to the blue energy profile shown by the blue line in the inset. A legend for the atom colours is shown in the inset. Figure reproduced with permission from Ref. [46]

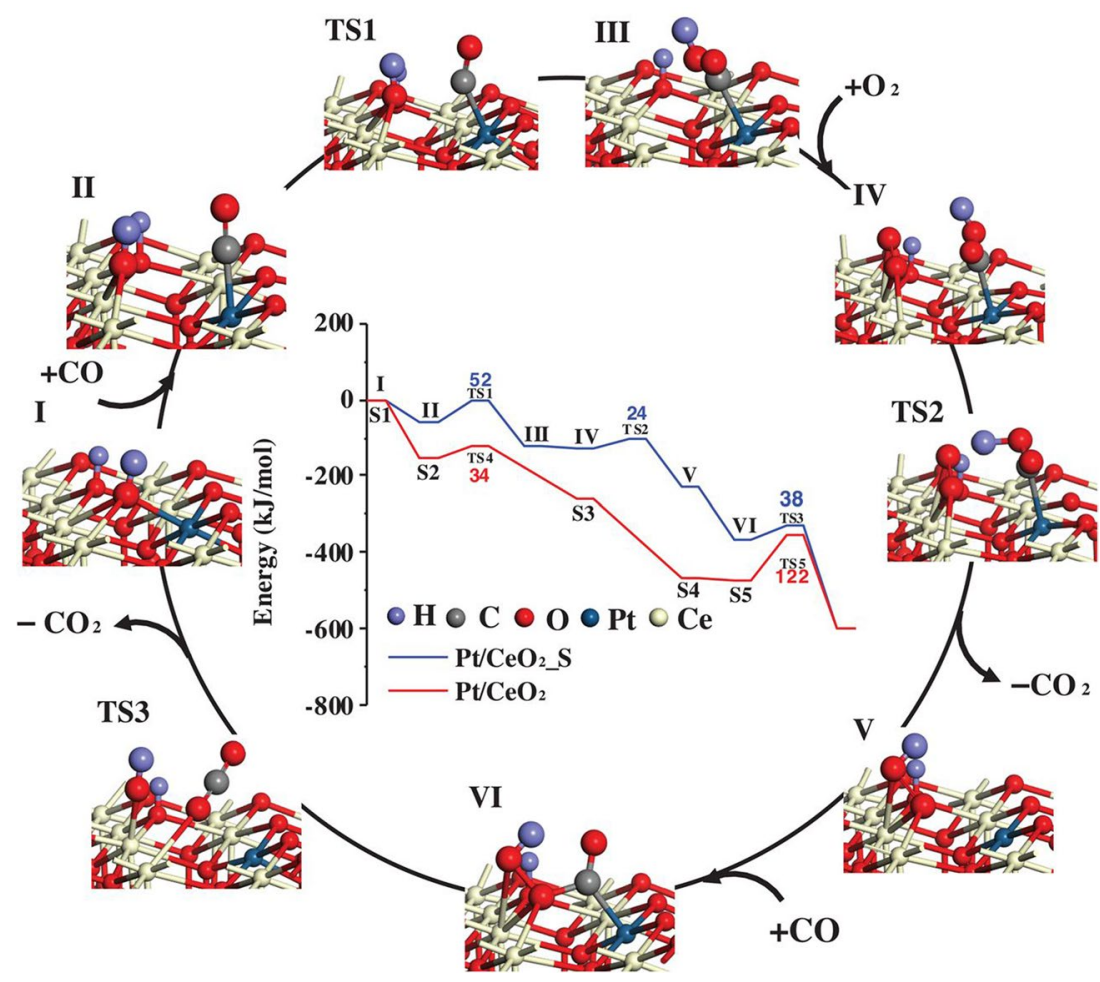

thermal stability of Pt adatoms, and to study if and how $\mathrm{CO}$ oxidation proceeds.

While $\mathrm{CO}$ oxidation is considered an ideal probe reaction to study the fundamentals of catalysis [54], it is certainly not the only reaction where SAC could make a significant impact. Liu and Corma have published an insightful summary of the potential applications in a variety of reactions [55], and highlight water-gas shift, selective hydrogenations, photocatalysis and electrocatalytic reactions as attractive targets. Isolated atom geometries are known to be useful for hydrogenation reactions in closely related, so-called single atom alloys (SAA) [56], where incorporated Pt and $\mathrm{Pd}$ atoms, for example, dissociate $\mathrm{H}_{2}$ leading to spillover onto a more inert host metal where further chemistry takes place [57, 58]. Zhang and coworkers have shown that this concept extends to metal oxide supports, and specifically that $\mathrm{Pt}_{1} / \mathrm{FeO}_{\mathrm{x}}$ and $\mathrm{Ir}_{1} / \mathrm{FeO}_{\mathrm{x}}$ can catalyse the selective hydrogenation of nitroarenes [59]. Clearly then, it is important to get a grasp of which metals best perform in the relevant processes, which is $\mathrm{H}_{2}$ activation in this case. The authors also note that $\mathrm{Pd}_{1} / \mathrm{FeO}_{\mathrm{x}}$ and $\mathrm{Rh} / \mathrm{FeO}_{\mathrm{x}}$ are as reactive as $\mathrm{Pt}$ and Ir, but suffered from a lack of selectivity. This suggests that the adatom also interacts with the nitroarenes, and the authors claim the excellent performance of $\mathrm{Pt}_{1} / \mathrm{FeO}_{\mathrm{x}}$ is related to preferential adsorption of nitro groups. Similarly excellent performance was reported recently for $\mathrm{Pd}_{1}$ adatoms anchored on graphitic carbon nitride [60] and other carbon supported systems [61]. The only surface science work on this topic so far comes from Libuda and coworkers [62], who determined that the fourfold coordinated $\mathrm{Pt}^{2+}$ at step edges on $\mathrm{CeO}_{2}(111)$ are inactive for $\mathrm{H}_{2}$ dissociation. Again, it is reasonable to expect that charge state and coordination of an adatom would play a role in this process.

The importance of the electrocatalytic reactions for emerging energy-related applications cannot be overstated. Lowering the required overpotential remains the bottleneck for a number of important technologies including water splitting and artificial photosynthesis. There has been interest in testing "single atom" electrocatalysts, and while there is evidence these systems can perform well, the mechanism of this reaction is not well understood and the reason for the catalytic activity is not clear. At present, the field electrochemical surface science on oxides remains in its infancy, but there are signs that it is becoming possible to perform electrochemical measurements on UHV prepared samples with a good degree of control [63]. As this line of research continues to mature, testing the stability and activity of the SAC model systems discussed above presents an opportunity to make a significant impact in an important and rapidly expanding area.

Over the last few years, researchers have noted a similarity between SAC and homogeneous catalysts [64, 65], because the charge state of the metal and its coordination sphere seem to define catalytic activity. There is much excitement at the prospect that SAC could bridge the gap between these fields [64], with isolated adatom active sites providing the extreme selectivity typical of homogeneous catalysts. The idea is then to target reactions typically performed by organometallic 
compounds in solution, and try to "heterogenize" the reaction using the same metal. Both Lang et al. [66] and Wang et al. [67] have demonstrated oxide supported Rh-SACs can catalyse hydroformylation of olefins as well as Rh-based homogeneous catalysts. In the latter case, the authors proposed an intriguing reaction pathway in which $\mathrm{H}_{2}$ dissociation occurs at $\mathrm{Rh}$ adatoms leading to surface $\mathrm{OH}$ groups, which take part in the reaction with $\mathrm{CO}$ and propene coadsorbed at $\mathrm{Rh}_{1}$. While most systems still prefer oxide supports, an alternative approach is to try to tailor supports to mimic the active centre of homogeneous catalysts. Chen et al. [68] anchored Pd on a graphitic carbon nitride support to mimic the coordination environment in Pd acetate, which is usually used to catalyse Suzuki couplings in solution. The result was a highly effective catalyst, which the authors attribute to the ligands, which provide an adaptive coordination of the palladium, and participates in the adsorption, stabilization and activation of the intermediates.

Clearly, the ability to tailor the atomic-scale structure of the active site is going to be key going forwards in the field of SAC. Ideally then, the extensive literature in homogeneous catalysis should serve as inspiration for which systems to study, but $\mathrm{O}^{2-}$ is not a particularly common ligand in organometallic complexes [69]. If we wish to keep using metal oxide supports, it is vital to learn how $\mathrm{O}^{2-}$ coordination affects adsorption processes and reactivity. Moving away from oxides, there are many examples of single atom catalysts supported by carbon, carbon nitride and other materials [2], but as yet there is relatively little surface science work investigating the catalytic properties of metal adatoms adsorbed on these supports. One exciting avenue is combining SAC with $2 \mathrm{D}$ materials, in particular graphene, $\mathrm{g}-\mathrm{C}_{3} \mathrm{~N}_{4}$, and $\mathrm{MoS}_{2}$, with the aim to modulate the reactivity of metal atoms through unusual bonding environments and electronic environments. In the current author's opinion, SAC presents an exciting opportunity for surface science experiments to work hand in hand with theory to separate fact from fiction, and help determine what possibilities exist in this exciting area of research.

Acknowledgements Open access funding provided by Austrian Science Fund (FWF). GSP acknowledges funding from the Austrian Science Fund START prize Y 847-N20, and thanks Prof. Ulrike Diebold (TU Wien) and Zdenek Jakub (TU Wien) for critically reading the manuscript.

\section{Compliance with Ethical Standards}

Conflict of interest The authors report no conflict of interest.

Open Access This article is distributed under the terms of the Creative Commons Attribution 4.0 International License (http://creativeco mmons.org/licenses/by/4.0/), which permits unrestricted use, distribution, and reproduction in any medium, provided you give appropriate credit to the original author(s) and the source, provide a link to the Creative Commons license, and indicate if changes were made.

\section{References}

1. Liu J (2016) Catalysis by supported single metal atoms. ACS Catal 7:34-59

2. Yang XF, Wang A, Qiao B, Li J, Liu J, Zhang T (2013) Singleatom catalysts: a new frontier in heterogeneous catalysis. Acc Chem Res 46(8): 1740-1748

3. Zhang H, Liu G, Shi L, Ye J (2018) Single-atom catalysts: emerging multifunctional materials in heterogeneous catalysis. Adv Energy Mater 8:1701343

4. Flytzani-Stephanopoulos M, Gates BC (2012) Atomically dispersed supported metal catalysts. Catal Sci Technol 3:545-574

5. Jones J, Xiong H, DeLaRiva AT, Peterson EJ, Pham H, Challa SR, Qi G, Oh S, Wiebenga MH, Pereira Hernández XI, Wang Y, Datye AK (2016) Thermally stable single-atom platinum-onceria catalysts via atom trapping. Science 353:150-154

6. Liang S, Hao C, Shi Y (2015) The power of single-atom catalysis. ChemCatChem 7:2559-2567

7. Qiao B, Wang A, Yang X, Allard LF, Jiang Z, Cui Y, Liu J, Li J, Zhang T (2011) Single-atom catalysis of CO oxidation using $\mathrm{Pt}_{1} / \mathrm{FeO}_{\mathrm{x}}$. Nat Chem 3:634-641

8. Masatake H, Tetsuhiko K, Hiroshi S, Nobumasa Y (1987) Novel gold catalysts for the oxidation of carbon monoxide at a temperature far below $0{ }^{\circ} \mathrm{C}$. 16:405-408

9. Kaden WE, Wu T, Kunkel WA, Anderson SL (2009) Electronic structure controls reactivity of size-selected Pd clusters adsorbed on $\mathrm{TiO}_{2}$ surfaces. Science 326:826-829

10. Vajda S, Pellin MJ, Greeley JP, Marshall CL, Curtiss LA, Ballentine GA, Elam JW, Catillon-Mucherie S, Redfern PC, Mehmood F, Zapol P (2009) Subnanometre platinum clusters as highly active and selective catalysts for the oxidative dehydrogenation of propane. Nat Mater 8:213

11. Yoon B, Häkkinen H, Landman U, Wörz AS, Antonietti J-M, Abbet S, Judai K, Heiz U (2005) Charging effects on bonding and catalyzed oxidation of $\mathrm{CO}$ on $\mathrm{Au}_{8}$ clusters on $\mathrm{MgO}$. Science 307:403-407

12. Lei Y, Mehmood F, Lee S, Greeley J, Lee B, Seifert S, Winans RE, Elam JW, Meyer RJ, Redfern PC, Teschner D, Schlögl R, Pellin MJ, Curtiss LA, Vajda S (2010) Increased silver activity for direct propylene epoxidation via subnanometer size effects. Science 328:224-228

13. Abbet S, Sanchez A, Heiz U, Schneider WD, Ferrari AM, Pacchioni G, Rösch N (2000) Acetylene cyclotrimerization on supported size-selected Pdn clusters $(1 \leq \mathrm{n} \leq 30)$ : one atom is enough! J Am Chem Soc 122:3453-3457

14. Fu Q, Saltsburg H, Flytzani-Stephanopoulos M (2003) Active nonmetallic $\mathrm{Au}$ and $\mathrm{Pt}$ species on ceria-based water-gas shift catalysts. Science 301:935

15. Flytzani-Stephanopoulos M (2014) Gold atoms stabilized on various supports catalyze the water-gas shift reaction. Acc Chem Res 47:783-792

16. Chen Y, Ji S, Chen C, Peng Q, Wang D, Li Y (2018) Singleatom catalysts: synthetic strategies and electrochemical applications. Joule 2:1242-1264

17. Datye A, Wang Y (2018) Atom trapping: a novel approach to generate thermally stable and regenerable single-atom catalysts. Natl Sci Rev 5:630-632

18. Mitchell S, Vorobyeva E, Pérez-Ramírez J (2018) The multifaceted reactivity of single-atom heterogeneous catalysts. Angew Chem Int Ed 57:15316-15329

19. Ding K, Gulec A, Johnson AM, Schweitzer NM, Stucky GD, Marks LD, Stair PC (2015) Identification of active sites in CO oxidation and water-gas shift over supported Pt catalysts. Science 350:189-192 
20. Liu J (2017) Aberration-corrected scanning transmission electron microscopy in single-atom catalysis: PROBING the catalytically active centers. Chin J Catal 38:1460-1472

21. Aleksandrov HA, Neyman KM, Hadjiivanov KI, Vayssilov GN (2016) Can the state of platinum species be unambiguously determined by the stretching frequency of an adsorbed $\mathrm{CO}$ probe molecule? PCCP 18:22108-22121

22. DeRita L, Dai S, Lopez-Zepeda K, Pham N, Graham GW, Pan X, Christopher P (2017) Catalyst architecture for stable single atom dispersion enables site-specific spectroscopic and reactivity measurements of $\mathrm{CO}$ adsorbed to $\mathrm{Pt}$ atoms, oxidized Pt clusters, and metallic Pt clusters on $\mathrm{TiO}_{2}$. J Am Chem Soc 139:14150-14165

23. Thang HV, Pacchioni G, DeRita L, Christopher P (2018) Nature of stable single atom Pt catalysts dispersed on anatase $\mathrm{TiO}_{2}$. J Catal 367:104-114

24. Liang J, Yu Q, Yang X, Zhang T, Li J (2018) A systematic theoretical study on $\mathrm{FeO}_{\mathrm{x}}$-supported single-atom catalysts: $\mathrm{M}_{1} / \mathrm{FeO}_{\mathrm{x}}$ for CO oxidation. Nano Res 11:1599-1611

25. Li F, Li Y, Zeng XC, Chen Z (2015) Exploration of high-performance single-atom catalysts on support $\mathrm{M} 1 / \mathrm{FeOx}$ for $\mathrm{CO}$ oxidation via computational study. ACS Catal 5:544-552

26. Ghosh TK, Nair NN (2013) $\mathrm{Rh}_{1} / \gamma-\mathrm{Al}_{2} \mathrm{O}_{3}$ single-atom catalysis of $\mathrm{O}_{2}$ activation and $\mathrm{CO}$ oxidation: Mechanism, effects of hydration, oxidation state, and cluster size. ChemCatChem 5:1811-1821

27. Dvořák F, Farnesi Camellone M, Tovt A, Tran N-D, Negreiros FR, Vorokhta M, Skála T, Matolínová I, Mysliveček J, Matolín V, Fabris S (2016) Creating single-atom Pt-ceria catalysts by surface step decoration. Nat Commun 7:10801-10801

28. Bliem R, McDermott E, Ferstl P, Setvin M, Gamba O, Pavelec J, Schneider MA, Schmid M, Diebold U, Blaha P, Hammer L, Parkinson GS (2014) Subsurface cation vacancy stabilization of the magnetite (001) surface. Science 346:1215-1218

29. Arndt B, Bliem R, Gamba O, van der Hoeven JES, Noei H, Diebold U, Parkinson GS, Stierle A (2016) Atomic structure and stability of magnetite $\mathrm{Fe}_{3} \mathrm{O}_{4}(001)$ : An X-ray view. Surf Sci 653:76-81

30. Meier M, Jakub Z, Balajka J, Hulva J, Bliem R, Thakur PK, Lee TL, Franchini C, Schmid M, Diebold U, Allegretti F, Duncan DA, Parkinson GS (2018) Probing the geometry of copper and silver adatoms on magnetite: quantitative experiment versus theory. Nanoscale 10:2226-2230

31. Ryan PTP, Jakub Z, Balajka J, Hulva J, Meier M, Kuchle JT, Blowey PJ, Thakur PK, Franchini C, Payne DJ, Woodruff DP, Rochford LA, Allegretti F, Lee TL, Parkinson GS, Duncan DA (2018) Direct measurement of Ni incorporation into $\mathrm{Fe}_{3} \mathrm{O}_{4}(001)$. Phys Chem Chem Phys 20:16469-16476

32. Bliem R, Pavelec J, Gamba O, McDermott E, Wang Z, Gerhold S, Wagner M, Osiecki J, Schulte K, Schmid M, Blaha P, Diebold U, Parkinson GS (2015) Adsorption and incorporation of transition metals at the magnetite $\mathrm{Fe}_{3} \mathrm{O}_{4}(001)$ surface. Phys Rev B 92:075440

33. Novotny Z, Argentero G, Wang Z, Schmid M, Diebold U, Parkinson GS (2012) Ordered array of single adatoms with remarkable thermal stability: $\mathrm{Au} / \mathrm{Fe}_{3} \mathrm{O}_{4}(001)$. Phys Rev Lett 108:216103

34. Bliem R, Kosak R, Perneczky L, Novotny Z, Gamba O, Fobes D, Mao Z, Schmid M, Blaha P, Diebold U, Parkinson GS (2014) Cluster nucleation and growth from a highly supersaturated adatom phase: silver on magnetite. ACS Nano 8:7531-7537

35. Bliem R, van der Hoeven JE, Hulva J, Pavelec J, Gamba O, de Jongh PE, Schmid M, Blaha P, Diebold U, Parkinson GS (2016) Dual role of $\mathrm{CO}$ in the stability of subnano Pt clusters at the $\left.\mathrm{Fe}_{3} \mathrm{O}_{4} 001\right)$ surface. Proc Natl Acad Sci USA 113:8921-8926

36. Bartelt NC, Nie S, Starodub E, Bernal-Villamil I, Gallego S, Vergara L, McCarty KF, de la Figuera J (2013) Order-disorder phase transition on the (100) surface of magnetite. Phys Rev B $88: 235436$
37. Duan S, Wang R, Liu J (2018) Stability investigation of a high number density $\mathrm{Pt}_{1} / \mathrm{Fe}_{2} \mathrm{O}_{3}$ single-atom catalyst under different gas environments by HAADF-STEM. Nanotechnology 29:204002

38. Setvin M, Reticcioli M, Poelzleitner F, Hulva J, Schmid M, Boatner LA, Franchini C, Diebold U (2018) Polarity compensation mechanisms on the perovskite surface $\mathrm{KTaO}_{3}(001)$. Science 359:572-575

39. Setvin M, Hulva J, Parkinson GS, Schmid M, Diebold U (2017) Electron transfer between anatase $\mathrm{TiO}_{2}$ and an $\mathrm{O}_{2}$ molecule directly observed by atomic force microscopy. Proc Natl Acad Sci USA 114:E2556-E2562

40. Bliem R, van der Hoeven JES, Hulva J, Pavelec J, Gamba O, de Jongh PE, Schmid M, Blaha P, Diebold U, Parkinson GS (2016) Dual role of $\mathrm{CO}$ in the stability of subnano Pt clusters at the Fe3O4(001) surface. Proc Natl Acad Sci USA 113:8921-8926

41. Parkinson GS, Novotny Z, Argentero G, Schmid M, Pavelec J, Kosak R, Blaha P, Diebold U (2013) Carbon monoxideinduced adatom sintering in a $\mathrm{Pd}-\mathrm{Fe}_{3} \mathrm{O}_{4}$ model catalyst. Nat Mater 12:724-728

42. Sterrer M, Yulikov M, Risse T, Freund H-J, Carrasco J, Illas F, Di Valentin C, Giordano L, Pacchioni G (2006) When the reporter induces the effect: unusual IR spectra of $\mathrm{CO}$ on $\mathrm{Au}_{1} /$ $\mathrm{MgO}(001) / \mathrm{Mo}(001)$. Angew Chem Int Ed 45:2633-2635

43. Rim KT, Eom D, Chan S-W, Flytzani-Stephanopoulos M, Flynn GW, Wen X-D, Batista ER (2012) Scanning tunneling microscopy and theoretical study of water adsorption on $\mathrm{Fe}_{3} \mathrm{O}_{4}$ : Implications for catalysis. J Am Chem Soc 134:18979-18985

44. Rim KT, Eom D, Liu L, Stolyarova E, Raitano JM, Chan S-W, Flytzani-Stephanopoulos M, Flynn GW (2009) Charging and chemical reactivity of gold nanoparticles and adatoms on the (111) surface of single-crystal magnetite: A scanning tunneling microscopy/spectroscopy study. J Phys Chem C 113:10198-10205

45. Yu X, Tian X, Wang S (2014) Adsorption of Ni, Pd, Pt, Cu, Ag and $\mathrm{Au}$ on the $\mathrm{Fe}_{3} \mathrm{O}_{4}(111)$ surface. Surf Sci 628:141-147

46. Nie L, Mei D, Xiong H, Peng B, Ren Z, Hernandez XIP, DeLaRiva A, Wang M, Engelhard MH, Kovarik L, Datye AK, Wang Y (2017) Activation of surface lattice oxygen in single-atom Pt/ $\mathrm{CeO}_{2}$ for low-temperature $\mathrm{CO}$ oxidation. Science 358:1419-1423

47. Wang C, Gu X-K, Yan H, Lin Y, Li J, Liu D, Li W-X, Lu J (2017) Water-mediated Mars-van Krevelen mechanism for CO oxidation on ceria-supported single-atom $\mathrm{Pt}_{1}$ catalyst. ACS Catal 7:887-891

48. Therrien AJ, Groden K, Hensley AJR, Schilling AC, Hannagan RT, Marcinkowski MD, Pronschinske A, Lucci FR, Sykes ECH, McEwen J-S (2018) Water activation by single Pt atoms supported on a $\mathrm{Cu}_{2} \mathrm{O}$ thin film. J Catal 364:166-173

49. Setvín M, Daniel B, Mansfeldova V, Kavan L, Scheiber P, Fidler M, Schmid M, Diebold U (2014) Surface preparation of $\mathrm{TiO}_{2}$ anatase (101): pitfalls and how to avoid them. Surf Sci 626:61-67

50. Setvín M, Aschauer U, Scheiber P, Li Y-F, Hou W, Schmid M, Selloni A, Diebold U (2013) Reaction of $\mathrm{O}_{2}$ with subsurface oxygen vacancies on $\mathrm{TiO}_{2}$ anatase (101). Science 341:988-991

51. Dahal A, Dohnálek Z (2017) Formation of metastable water chains on anatase $\mathrm{TiO}_{2}(101)$. J Phys Chem C 121:20413-20418

52. Aschauer U, He Y, Cheng H, Li S-C, Diebold U, Selloni A (2010) Influence of subsurface defects on the surface reactivity of $\mathrm{TiO}_{2}$ : water on anatase (101). J Phys Chem C 114:1278-1284

53. Gong X-Q, Selloni A, Dulub O, Jacobson P, Diebold U (2008) Small $\mathrm{Au}$ and Pt clusters at the anatase $\mathrm{TiO}_{2}(101)$ surface: Behavior at terraces, steps, and surface oxygen vacancies. J Am Chem Soc 130:370-381

54. Freund H-J, Meijer G, Scheffler M, Schlögl R, Wolf M (2011) CO oxidation as a prototypical reaction for heterogeneous processes. Angew Chem Int Ed 50:10064-10094 
55. Liu L, Corma A (2018) Metal catalysts for heterogeneous catalysis: from single atoms to nanoclusters and nanoparticles. Chem Rev 118:4981-5079

56. Kyriakou G, Boucher MB, Jewell AD, Lewis EA, Lawton TJ, Baber AE, Tierney HL, Flytzani-Stephanopoulos M, Sykes ECH (2012) Isolated metal atom geometries as a strategy for selective heterogeneous hydrogenations. Science 335:1209-1212

57. Giannakakis G, Flytzani-Stephanopoulos M, Sykes ECH (2018) Single-atom alloys as a reductionist approach to the rational design of heterogeneous catalysts. Acc Chem Res 52(1):237-247

58. Darby MT, Stamatakis M, Michaelides A, Sykes ECH (2018) Lonely atoms with special gifts: Breaking linear scaling relationships in heterogeneous catalysis with single-atom alloys. J Phys Chem Lett 9:5636-5646

59. Wei H, Liu X, Wang A, Zhang L, Qiao B, Yang X, Huang Y, Miao S, Liu J, Zhang T (2014) FeOx-supported platinum single-atom and pseudo-single-atom catalysts for chemoselective hydrogenation of functionalized nitroarenes. Nat Commun 5:5634

60. Vilé G, Albani D, Nachtegaal M, Chen Z, Dontsova D, Antonietti M, López N, Pérez-Ramírez J (2015) A stable single-site palladium catalyst for hydrogenations. Angew Chem Int Ed 54:11265-11269

61. Li H, Zhang H-x, Xu YX, Guo B-s J-j (2018) Carbon-supported metal single atom catalysts. New Carbon Mater 33:1-11

62. Lykhach Y, Figueroba A, Camellone MF, Neitzel A, Skála T, Negreiros FR, Vorokhta M, Tsud N, Prince KC, Fabris S, Neyman KM, Matolín V, Libuda J (2016) Reactivity of atomically dispersed $\mathrm{Pt}^{2+}$ species towards $\mathrm{H}_{2}$ : model $\mathrm{Pt}-\mathrm{CeO}_{2}$ fuel cell catalyst. PCCP 18:7672-7679

63. Faisal F, Stumm C, Bertram M, Waidhas F, Lykhach Y, Cherevko S, Xiang F, Ammon M, Vorokhta M, Šmíd B, Skála T, Tsud N, Neitzel A, Beranová K, Prince KC, Geiger S, Kasian O, Wähler T, Schuster R, Schneider MA, Matolín V, Mayrhofer KJJ, Brummel
O, Libuda J (2018) Electrifying model catalysts for understanding electrocatalytic reactions in liquid electrolytes. Nat Mater 17:592-598

64. Cui X, Li W, Ryabchuk P, Junge K, Beller M (2018) Bridging homogeneous and heterogeneous catalysis by heterogeneous single-metal-site catalysts. Nat Catal 1:385-397

65. Chen F, Jiang X, Zhang L, Lang R, Qiao B (2018) Single-atom catalysis: Bridging the homo- and heterogeneous catalysis. Chin J Catal 39:893-898

66. Lang R, Li T, Matsumura D, Miao S, Ren Y, Cui Y-T, Tan Y, Qiao B, Li L, Wang A, Wang X, Zhang T (2016) Hydroformylation of olefins by a rhodium single-atom catalyst with activity comparable to $\mathrm{RhCl}\left(\mathrm{PPh}_{3}\right)_{3}$. Angew Chem Int Ed 55:16054-16058

67. Wang L, Zhang W, Wang S, Gao Z, Luo Z, Wang X, Zeng R, Li A, Li H, Wang M, Zheng X, Zhu J, Zhang W, Ma C, Si R, Zeng J (2016) Atomic-level insights in optimizing reaction paths for hydroformylation reaction over $\mathrm{Rh} / \mathrm{CoO}$ single-atom catalyst. Nat Commun 7:14036

68. Chen Z, Vorobyeva E, Mitchell S, Fako E, Ortuño MA, López N, Collins SM, Midgley PA, Richard S, Vilé G, Pérez-Ramírez J (2018) A heterogeneous single-atom palladium catalyst surpassing homogeneous systems for Suzuki coupling. Nat Nanotech 13:702-707

69. Gates BC, Flytzani-Stephanopoulos M, Dixon DA, Katz A (2017) Atomically dispersed supported metal catalysts: perspectives and suggestions for future research. Catal Sci Technol 7:4259-4275

Publisher's Note Springer Nature remains neutral with regard to jurisdictional claims in published maps and institutional affiliations. 